\section{$\underset{\substack{\text { hommes } \\ \text { \& migrations }}}{ }$}

\section{Hommes \& migrations}

Revue française de référence sur les dynamiques

migratoires

\section{$1279 \mid 2009$}

L'Afrique en mouvement

\title{
Aminata Traoré, L’Afrique humiliée
}

Hachette littératures, coll. Pluriel, 2009, 7,90 euros

\section{Nicolas Treiber}

\section{(2) OpenEdition \\ 12 Journals}

Édition électronique

URL : http://journals.openedition.org/hommesmigrations/361

DOI : 10.4000/hommesmigrations.361

ISSN : 2262-3353

Éditeur

Musée national de l'histoire de l'immigration

\section{Édition imprimée}

Date de publication : 1 mai 2009

Pagination : 208-209

ISSN : 1142-852X

\section{Référence électronique}

Nicolas Treiber, «Aminata Traoré, L'Afrique humiliée », Hommes \& migrations [En ligne], 1279 | 2009, mis en ligne le 29 mai 2013, consulté le 23 septembre 2020. URL : http://journals.openedition.org/ hommesmigrations/361 ; DOI : https://doi.org/10.4000/hommesmigrations.361

Ce document a été généré automatiquement le 23 septembre 2020.

Tous droits réservés 


\title{
Aminata Traoré, L'Afrique humiliée
}

Hachette littératures, coll. Pluriel, 2009, 7,90 euros

\author{
Nicolas Treiber
}

\section{RÉFÉRENCE}

Aminata Traoré - L'Afrique humiliée, Hachette littératures, coll. Pluriel, 2009, 7,90 euros

1 En ces temps délétères, l'Afrique est en première ligne de notre monde ballotté par la crise économique. La parution en poche de L'Afrique humiliée d'Aminata Traoré offre une occasion bienvenue de participer aux débats actuels, de s'interroger sur les causes d'une possible faillite du capitalisme financier et les moyens de le réformer.

2 Ancienne ministre de la culture du Mali, fonctionnaire international et militante altermondialiste, Aminata Traoré forme une critique rigoureuse des modalités et des conséquences de l'ouverture de l'Afrique au marché mondial. Son point de vue éclaire de biais les rouages de la mondialisation néolibérale, "la nouvelle forme d'organisation de la ponction". Le constat est amer. "La logique économique qui met l'Afrique à genoux secrète la pauvreté, la précarité et le mécontentement dans les pays riches ${ }^{1} . "$

3 Ce livre réquisitoire, publié avant la crise de 2008, dénonce cinquante années de mensonges et d'hypocrisie au nom du développement. Et il y a urgence, tant le double langage hérité des habitudes coloniales continue de prospérer en Afrique. En témoigne le discours de Nicolas Sarkozy prononcé le 26 juillet 2007 à Dakar. Des propos qu'Aminata Traoré entend déconstruire, auxquelles elle confronte d'autres paroles, celles d'Aimé Césaire, ou Cheikh Hamidou Kane qui signe la préface de L'Afrique humiliée.

4 Un discours donc, comme point d'orgue d'une série historique récente, jalonnée de drames et de crises aux noms évocateurs. L'automne des "banlieues", Ceuta et Mellila... Des images, et la logique implacable de pays européens qui, autant à l'extérieur qu'à l'intérieur de leurs frontières, restent sourds aux attentes que leur modèle de développement suscite chez ceux qui restent à la marge. Et pour cause. Le modèle est biaisé. Il autorise les admonestations telles que "l'homme africain n'est pas assez rentré 
dans l'histoire" de Nicolas Sarkozy, en masquant la structure même de cette histoire, qui est piégée. "En enfilant la camisole de force du libéralisme économique, les pays dont les migrants sont originaires se sont laissés piéger (...) Le marché mondial ouvert à tous, source de prospérité et de bonheur pour tous, est la perfection que les gagnants et les maitres de l'ordre actuel continuent de nous faire miroiter'."

5 Aminata Traoré entreprend la généalogie consternante de cet état de fait. Des programmes d'ajustement structurels, ayant pour résultat une "excision économique", à l'échec de l'aide au développement, en passant par l'étouffement de la filière malienne du coton par les subventions d'une Europe qui protège ses exportations, la constante, c'est la mise sous tutelle. En Afrique, la croissance profite aux "entreprises étrangères qui s'enrichissent et permettent à leurs interlocuteurs et alliés locaux d'en faire autant au détriment de l'immense majorité des Africains et de l'environnement ${ }^{3}$."

6 Les Africains ne sont pas exempts de reproches. L'auteur souligne le manque de courage, de lucidité, les trahisons et l'aliénation culturelle dont souffrent certains de ses pairs. Sur ce dernier point, elle relève cependant que l'inégalité qui caractérise les rapports entre l'Afrique et l'Europe, repose sur un véritable "viol de l'imaginaire". "L'une des règles du jeu consiste à faire intérioriser aux Africains le sentiment de leur échec à saisir et exploiter les opportunités du système $e^{4}$." Le regard tendu vers des frontières qui leurs tournent le dos, les immigrés qui arpentent la dougouma sira, la voie terrestre de l'exil, découvrent au bout du Sahara une impasse. Leur origine hypothèque leur réussite. La peur de l'échec et la mort sociale hantent leur retour.

7 Le sort des immigrés clandestins commence à faire exemple. Leurs naufrages renvoient symboliquement à celui des règles d'un jeu qui produit des perdants. L'enjeu, selon Aminata Traoré, est crucial : il s'agit pour les Africains de se réapproprier leurs biens et leurs destins. Afin de "cesser d'être des exilés et des naufragés en nous-mêmes, chez nous et partout où nous allons". Sur le plan idéologique, elle prolonge une idée chère à Cheikh Hamidou Kane : celle du "recours au sources", aux valeurs identitaires fondamentales. Garantes des conditions de la survie, les femmes africaines sont le pivot de cette régénération, "les gardiennes du temple". Elles peuvent retenir cette jeunesse prête à se sacrifier. La conscience de l'ambiguïté de l'aventure avance, comme chez ce jeune de Bamako: "Tu pars jeune et fort, tu as toutes les chances de ne jamais revenir, ou de revenir vieux, usé et pauvre parmi les tiens ${ }^{6}$."

8 Au niveau des politiques migratoires, Aminata Traoré appelle de ses vœux une immigration circulaire. Accepter de prendre et de donner, afin de poursuivre l'histoire d'un monde tissé d'échanges entre les peuples. Afin de ne pas oublier que si "nul ne sort indemne de l'expérience de la rencontre ${ }^{7 "}$, il importe de ne pas perdre le chemin de soi.

\section{NOTES}

1. Aminata Traoré, L'Afrique humiliée, Paris Hachette littérature, coll. Pluriel, 2009, p. 184.

2. idem, p. 76.

3. idem, p. 205. 
4. idem, p. 93.

5. Idem, p. 147.

6. idem, p. 289.

7. idem, p. 269 